\title{
Individual and Contextual Variation in Thomas Langur Male Loud Calls
}

\author{
Serge A. Wich*, Sonja Koski†, Han de Vries*, Carel P. van Schaik $\ddagger$ \\ *Utrecht University, Behavioural Biology, Utrecht, The Netherlands; $\dagger$ Helsinki \\ University, Department of Ecology and Systematics, Division of Population \\ Biology, Helsinki, Finland; $\$$ Biological Anthropology and Anatomy, \\ Duke University, Durham, NC, USA
}

\begin{abstract}
Individual and contextual differences in male loud calls of wild Thomas langurs (Presbytis thomasi) were studied in northern Sumatra, Indonesia. Loud calls were given in the following contexts: morning calls, vocal responses to other groups, between-group encounter calls and alarm calls. Loud call spectrograms were analysed for a large number of variables. With discriminant analyses, 14 variables were found to be important in distinguishing individuals and contexts. Loud calls were assigned to the correct individual in $95.6 \%$ of the cases (91.8\% with 'leave-one-out' validation) and to the correct context in $52.2 \%$ of the cases $(39.0 \%$ with 'leave-one-out' validation). Further analyses with two-way ANOVAs showed significant differences in both temporal and frequency variables between individuals and contexts. Loud calls seemed to differ between the contexts in functionally meaningful ways, relating to the distance of the intended receivers and to the urgency of the message. Observation showed that females in the caller's group collected infants more often in the between-group encounter context and in the alarm call context than in the vocal exchange context. These differential responses suggest that the monkeys also perceive the measurable differences in loud call characteristics between the various contexts.

Corresponding author: Serge A. Wich, Utrecht University, Behavioural Biology, PO Box 80086, 3508 TB, Utrecht, The Netherlands. E-mail: s.a.wich@, bio.uu.nl
\end{abstract}

\section{Introduction}

Evidence for individual variation in long distance vocalizations or loud calls exists in several primate species (e.g. Pan troglodytes: Marler and Hobbett 1975; Cercocebus albigina: Waser 1977; Cebuella pygmaeus: Snowdon and Cleveland 
1980; Ateles geoffroyi: Chapman \& Weary 1990; Presbytis thomasi: Steenbeek $\&$ Assink 1998). Individual variation in the acoustic features of loud calls may be adaptive for several reasons. It may permit individual recognition and this could help in coordinating group movement, re-establishing contact between individuals that have become separated, or distinguishing members of neighbouring groups from those of strangers (Ydenberg et al. 1988; Chapman \& Lefebvre 1990; Wich et al. 2002). This can be especially important in species where infanticidal attempts are more likely to come from strange or neighbouring males. For example, in Thomas langurs strange males are more likely to be infanticidal than neighbours ( $P$. thomasi: Sterck 1995; Wich et al. 2002). Loud call variation could also indicate male quality and influence female choice (Steenbeek \& Assink 1998) and male-male competition (Steenbeek et al. 1999).

Also, vocalizations of the same individual vary among social contexts in some species (C. albigina: Waser 1977; P. troglodytes: Clark \& Wrangham 1993; Alouatta seniculus: Vercauteren-Drubbel \& Gautier 1993; Callithrix jacchus: Nocross and Newman 1993). Contextual variation in call features can produce acoustically distinct categories with no intermediate call types or be graded, with continuous variation between the call types (Hammerschmidt \& Fischer 1998).

In this study we investigated both individual and contextual variation in loud calls (i.e. all long-distance vocalizations) of wild Thomas langurs, a medium sized (7-8 kg, Sterck 1995) arboreal colobine species that is endemic to Northern Sumatra, Indonesia. Populations comprise breeding groups with one male and several females, plus all-male bands and solitary males (Sterck 1995, 1997). Males always leave their natal group upon maturation, whereas females usually remain in their natal home range, but sometimes leave the natal group and join another breeding group ('flexible philopatry'; Steenbeek 1999a). During between-group encounters males of opposing groups are often aggressive towards each other, but females are not (van Schaik et al. 1992; Steenbeek 1999b). Infanticide is mainly due to extra-group males and presumably has a major influence on the social organization of the Thomas langur (Sterck 1995; Steenbeek 1999a).

The aim of this paper is to re-examine Steenbeek \& Assink's (1998) conclusion, that male loud calls allow individual recognition with a larger and more balanced sample. In addition, the aim is to determine whether males use acoustically different loud calls in different contexts. Males give loud calls in a variety of contexts (morning calls, vocal responses, between-group encounters and predation threat) and acoustic variation would be expected if calls serve different, context-specific functions and convey context-specific information. To assess whether possible contextual differences in loud calls have any biological significance, we observed the reaction of females to loud calls that their resident male gave in different contexts. We expected to find variation in reactions because different contexts presumably entailed different risks to females and their offspring. 


\section{Methods}

\section{Study Site}

This study was conducted at Ketambe Research Station $\left(3^{\circ} 41^{\prime} \mathrm{N}, 97^{\circ} 39^{\prime} \mathrm{E}\right)$, Gunung Leuser National Park, Leuser Ecosystem, Sumatra, Indonesia. The study area consists of primary lowland rain forest and was described by Rijksen (1978) and van Schaik and Mirmanto (1985).

\section{Loud Call Recordings and Categories}

Loud calls were recorded from six adult males of six breeding groups. The history of each of these groups and the individuals therein is well known, as Thomas langurs have been studied in this area since 1988 (Sterck 1995; Steenbeek 1999a). Tape recordings of loud calls were made from Mar. 1998 to Jul. 1999 with a Sony WM-D6C-recorder and Sony ECM-T140 microphone (Sony Corp., Tokyo, Japan).

All loud calls were recorded opportunistically during all-day follows of the monkeys. When a loud call occurred, the identity of the caller, the time of day and the behavioural context were noted. The following behavioural contexts were distinguished: (1) Morning call (MC): male gives out a loud call in early morning before 6:30 from a sleeping tree; (2) Vocal response calls (VR): vocal communication of two or more groups at any time of the day, (excluding the morning calls), without visual contact between groups; (3) Between-group encounter calls (GE): male loud calls during a between-group encounter (i.e. approach to within $50 \mathrm{~m}$; Steenbeek 1999a) with a neighbouring group or an all-male band; (4) Alarm calls (AL): calls given when a predator has been seen or heard, always preceded by a large number of hiccups by the male. Likely predators for Thomas langurs are tigers (Panthera tigris); clouded leopards (Neofelis nebulosa); and pythons (Python recticulatus). In practice it was easy to assign a call to the right context as several groups were followed simultaneously and therefore the distances to other groups were known.

We also recorded female responses to the calls in all but the MC context, and particularly whether they collected their offspring after loud calls of their own male. Data from 17 females from nine different groups were analysed for this purpose and each female was observed several times in each context. These data were collected on $444 \mathrm{~d}$ with dawn to dusk follows.

\section{Acoustic Analyses}

Thomas langur loud calls last approx. 4 s (Fig. 1; for details: Steenbeek \& Assink 1998; Steenbeek 1999a). A loud call starts with a rapid build-up phase (first few $\mathrm{N}$-units) until it reaches the loudest middle phase (last few $\mathrm{N}$-units), after which it declines into a more quiet end phase (T-units). All N-units in the build-up phase and the middle phase of the call are harsh, non-tonal sounds and consist of an inhalation and exhalation part (e.g. N1in and N1ex). The frequency range is wide with most spectral energy concentrated around $1.2-3.0 \mathrm{kHz}$. The end phase 


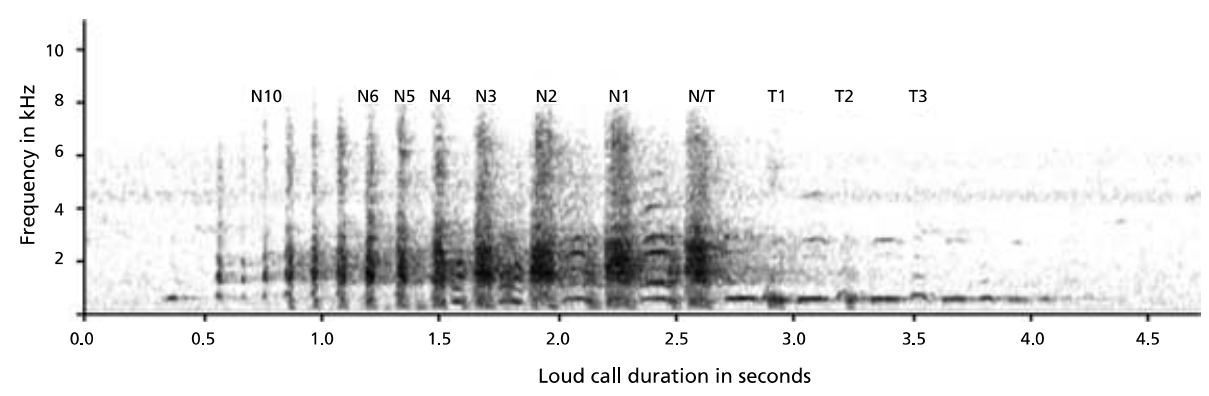

Fig. 1: Spectogram of male loud call

consists of tonal sounds (T-units), which may express frequency modulation during the exhalation part of an element. Fundamental frequencies are within the range that propagate well in a rain forest environment (Steenbeek \& Assink 1998) and can be heard by humans as far as ca. $700 \mathrm{~m}$ (S.A. Wich unpubl. data).

We analysed 192 calls from six males $(20,32,36,40,24,40)$, loud calls for each male respectively, with the Macintosh application Canary 1.2 (Cornell Laboratory of Ornithology, Ithaca, USA). For each male at least three calls were analysed for each context. A call was only analysed after visual inspection of the spectrogram showed that all parts of the call were recorded well and could be analysed.

Calls were converted into spectrograms (temporal measurements: filter bandwidth $353 \mathrm{~Hz}$, time resolution $1.4 \mathrm{~ms}$, frequency resolution $10.9 \mathrm{~Hz}$; frequency measurements: filter bandwidth $176 \mathrm{~Hz}$, time resolution $2.9 \mathrm{~ms}$, frequency resolution $5.4 \mathrm{~Hz}$ ). A total of 29 temporal and frequency variables were measured (cf. Steenbeek and Assink 1998) and these were: total duration (ms) of the call; the number of N-units; the number of T-units; frequency $(\mathrm{Hz})$ of N1in (inhale part of the N1 unit); frequency of N2in (inhale part of the N2 unit); frequency of N1ex (exhale part of the N1 unit) frequency of N2ex (exhale part of the $\mathrm{N} 2$ unit); and the time intervals (ms) between $\mathrm{N} 10-\mathrm{N} 8$; N10-N2; N10-N1; N8-N7; N8-N5; N8-N4; N8-N3; N8-N2; N8-N1; N7-N5; N7-N4; N7-N2; N7-N1; N5-N4; N5-N1; N4-N3; N4-N2; N4-N1; N3-N2; N3-N1; $\mathrm{N} 2-\mathrm{N} 1 ; \mathrm{N} 2-\mathrm{T} 2$.

\section{Statistical Analysis}

Discriminant analyses were used to examine differences between individuals and contexts (cf. Fischer et al. 2001). All variables were entered with the direct method (cf. Teixidor \& Byrne 1999; Fischer et al. 2001). We excluded one call variable (N2-T2), as some males did not produce T-units in all contexts. For validation of the group assignments made by the discriminant analysis we used the 'leave-one-out' procedure in SPSS 9.0, which leaves one variable out of the dataset and then tests how well the discriminant functions can predict group 
membership. The percentage of loud calls that could be assigned by chance to the correct individual or context is 100 divided by the number of individuals (6) or contexts (4). Variables that correlated fairly strongly with one of the discriminant functions ( $\mathrm{r}>0.45$, corresponding to $20 \%$ overlapping variance; $\mathrm{cf}$. Tabachnik and Fidell 2001) were used in a two-way factorial ANOvA to assess whether differences between individuals and contexts were significant.

Following each loud call we recorded for each female whether she collected her infant or not, for three call contexts: VR, GE and AL. Wilcoxon matched pair tests were used to find out whether the females collected their infants significantly more in some contexts, but not in others.

All tests were performed with SPSS 9.0 and considered significant when $\alpha<0.05$. Significance levels were corrected for with the sharper Bonferroni procedure (Hochberg 1988) to reduce the chance of type I errors.

\section{Results}

Before conducting the discriminant analyses an outlier analyses was performed using the Mahalanobis distance (Tabachnick and Fidell 2001). Five cases were considered outliers. Analyses performed with and without these cases essentially led to the same conclusions, so we decided not to exclude these cases. Of the 29 variables only 14 passed the tolerance criterion of 0.001 and were used in the discriminant analyses (Table 1).

The discriminant analyses showed that individuals gave acoustically distinct calls across all contexts (Fig. 2a). The first discriminant function accounted for $67.2 \%$ of the variance, the second for $23.0 \%$ and the remaining four functions for a combined variance of $9.8 \%$. With these functions $95.6 \%$ of the calls were

Table 1: Overview of variables

\begin{tabular}{|ll|}
\hline Variables & Description of variables \\
\hline N-units & Total number of N-units \\
T-units & Total number of T-units \\
Duration $(\mathrm{ms})$ & Duration from the first element to the last element \\
N2ex $(\mathrm{Hz})$ & Fundamental frequency in the middle of the element \\
N2in $(\mathrm{Hz})$ & Fundamental frequency in the middle of the element \\
N1ex $(\mathrm{Hz})$ & Fundamental frequency in the middle of the element \\
N1in $(\mathrm{Hz})$ & Fundamental frequency in the middle of the element \\
N10-N8 (ms) & Interval from N10-unit to N8-unit \\
N10-N2 (ms) & Interval from N10-unit to N8-unit \\
N10-N1 (ms) & Interval from N10-unit to N1-unit \\
N8-N7 (ms) & Interval from N8-unit to N7-unit \\
N8-N5 (ms) & Interval from N8-unit to N5-unit \\
N8-N4 (ms) & Interval from N8-unit to N4-unit \\
N8-N3 (ms) & Interval from N8-unit to N3-unit \\
\hline
\end{tabular}

Variables that passed the tolerance level in the discriminant analyses. 

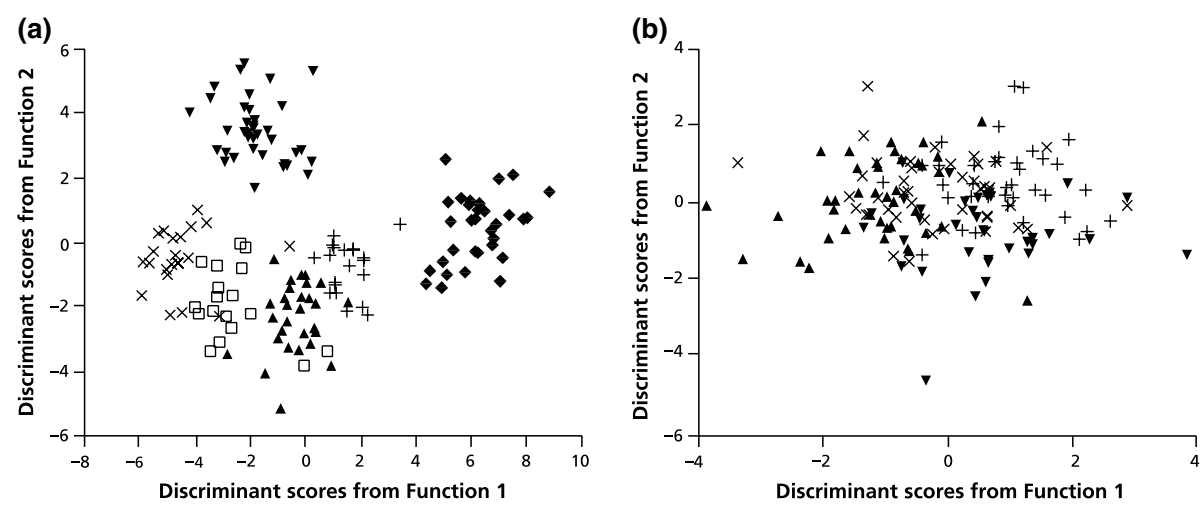

Fig. 2: (a) Scatter plot of individual scores for discriminant function 1 against discriminant function 2; (b) Scatter plot of contextual scores for discriminant function 1 against discriminant function 2

assigned to the correct individual (91.8\% with 'leave-one-out' validation). Predicted group memberships varied between $87-100 \%$ across individuals (87.0-97.3\% with 'leave-one-out validation').

With respect to contextual differences in loud calls, the first and second discriminant functions accounted for 72.0 and $23.3 \%$ of the variance, respectively (Fig. 2b). With these functions $52.2 \%$ of the calls were assigned to the correct context (39.0 with the 'leave-one-out' validation). The correct assignments varied between contexts from 20.5 to $70.3 \%(6.8-55.0 \%$ with the 'leave-one-out' validation). The context with the lowest correct assignment scores was VR with $20.8 \%$ (6.8\% with the 'leave-one-out validation'). We repeated these analyses excluding the VR context. The first and second discriminant functions accounted for, respectively, 70.2 and $29.8 \%$ of the variance. The percentage of calls that were assigned to the correct context was $67.2 \%$ ('leave-one-out' validation: $53.0 \%$ ). For each of the three contexts these percentages are (in brackets the 'leave-one-out' validation percentages): MC 66.7\% (50.0\%); GE 77.8\% (68.9\%); AL 57.8\% $(40.0 \%)$.

The VR contexts varied greatly in the number of T-units, and an ANCOVA with individuals entered as factors revealed a significant correlation between the number of T-units and the distance between two loud calling males (distance: $\mathrm{F} 1,37=108.9, \mathrm{p}<0.0001$; individual: F5,37 = 78.0, $\mathrm{p}<0.0001$; Fig. 3).

A main goal of our analysis is to find out which of the predictor variables discriminate well between the calls from different individuals and the calls performed in different contexts. To this end we inspected the correlations of the predictor variables with the discriminant functions and performed two-way ANOVAs for those variables correlated $(r>0.45)$ with any of the first two discriminant functions obtained from the analyses of individual and contextual differences. In these ANOvAs individual and context were entered as independent factors. The first discriminant function in the analyses for individual differences correlated most strongly with the frequency measures (N1in, N2in: $r=-0.65$ and 


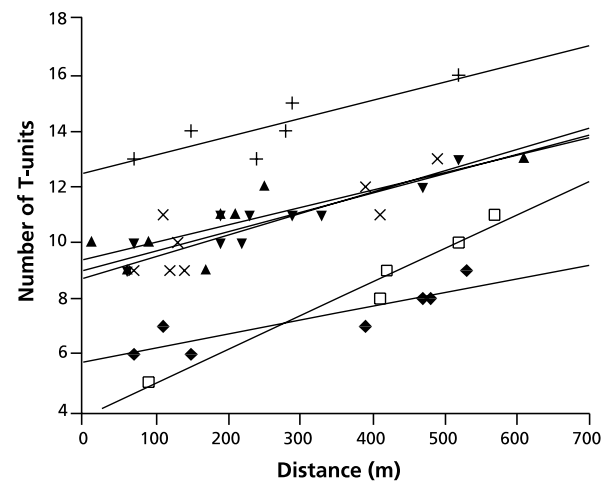

Fig. 3: The association between the distance of a recipient male and the number of T-units in the VR context

Table 2: Mean individual and context values for variables which correlated $(\mathrm{r}>0.45)$ with at least one of the two discriminant functions, mean (SD)

\begin{tabular}{|c|c|c|c|c|}
\hline Measure & $\begin{array}{l}\text { Mean } \\
\text { individuals }\end{array}$ & F-value & $\begin{array}{l}\text { Mean } \\
\text { contexts }\end{array}$ & F-value \\
\hline Duration (ms) & $3716.0(378.5)$ & $\mathrm{F} 5,168=75.6^{* *}$ & $3764.2(160.3)$ & $\mathrm{F} 3,168=16.6^{* *}$ \\
\hline $\mathrm{N} 10-\mathrm{N} 8(\mathrm{~ms})$ & $179.9(7.4)$ & $\mathrm{F} 5,154=16.3^{* *}$ & $180.9(5.7)$ & $\mathrm{F} 3,154=12.5^{* *}$ \\
\hline N10-N1 (ms) & $1567.9(79.3)$ & $\mathrm{F} 5,155=14.8^{* *}$ & $1582.4(47.7)$ & $\mathrm{F} 3,155=7.0^{*}$ \\
\hline N-units (number) & $12.4(1.8)$ & $\mathrm{F} 5,168=59.8^{* *}$ & $12.7(0.4)$ & $\mathrm{F} 3,168=4.3^{*}$ \\
\hline T-units (number) & $9.5(2.9)$ & $\mathrm{F} 5,168=155.1^{* *}$ & $9.8(0.8)$ & $\mathrm{F} 3,168=13.2^{* *}$ \\
\hline N1in $(\mathrm{Hz})$ & $512.6(254.5)$ & $\mathrm{F} 5,167=294.2^{* *}$ & $609.6(5.8)$ & $F 3,167=2.6$ \\
\hline N2in $(\mathrm{Hz})$ & $604.4(61.7)$ & $\mathrm{F} 5,166=260.9 * *$ & $604.6(7.0)$ & $\mathrm{F} 3,166=5.5^{* *}$ \\
\hline
\end{tabular}

$* * \mathrm{p}<0.01, * \mathrm{p}<0.05$.

-0.64 , respectively) and the second discriminant function correlated most strongly with the number of $\mathrm{N}$ - and $\mathrm{T}$-units ( $\mathrm{r}=0.44$ for both). The first discriminant function in the analyses for contextual differences correlated most strongly with temporal measures (duration: $\mathrm{r}=0.53, \mathrm{~N} 10-\mathrm{N} 1: \mathrm{r}=0.45$ ). The second discriminant function correlated with the temporal measure N10-N8 $(r=-0.62)$. Twoway factorial ANOVAs, conducted on the seven variables that gave a correlation coefficient greater than $r=0.45$ with one of the two discriminant functions, revealed significant differences among individuals for all variables and revealed significant differences among contexts for all variables except Nlin (Table 2). Notably, Tukey honest significant difference post hoc test revealed that duration and the interval N10-N1 were significantly shorter in the GE context than in the $\mathrm{AL}$ and $\mathrm{MC}$ contexts (duration GE-MC $\mathrm{t}_{\mathrm{s}}=-7.42$, $\mathrm{df}=94, \mathrm{p}<0.05$, and GEAL $t_{\mathrm{s}}=-5.53, \mathrm{df}=94, \mathrm{p}<0.05 ; \mathrm{N} 10-\mathrm{N} 1:$ GE-MC $\mathrm{t}_{\mathrm{s}}=-4.22, \quad \mathrm{df}=89$, $\mathrm{p}<0.05$, and GE-AL $\mathrm{t}_{\mathrm{s}}=-4.04, \mathrm{df}=87, \mathrm{p}<0.05$; Table 3). The number of T-units was significantly lower in the GE than the AL and MC contexts (GE-AL 
Table 3: The number of $\mathrm{T}$ - and $\mathrm{N}$-units in different contexts, mean (SD; $\mathrm{n})$

\begin{tabular}{|lllll|}
\hline & MC & VR & GE & AL \\
\hline Duration (ms) & $3926.0(384.3 ; 48)$ & $3752.0(432.2 ; 48)$ & $3548.7(488.3 ; 48)$ & $3830.2(474.3 ; 48)$ \\
N10-N1 (Hz) & $1625.0(101.6 ; 43)$ & $1542.8(146.0 ; 47)$ & $1539(127.0 ; 48)$ & $1622.3(125.0 ; 41)$ \\
N-units (number) & $12.1(2.3 ; 48)$ & $12.6(3.0 ; 48)$ & $13.1(2.0 ; 48)$ & $12.8(3.1 ; 48)$ \\
T-units (number) & $10.8(3.0 ; 48)$ & $10.1(3.0 ; 48)$ & $8.8(3.4 ; 48)$ & $9.6(2.9 ; 48)$ \\
\hline
\end{tabular}

$\mathrm{t}_{\mathrm{s}}=-4.77$, df $=94, \mathrm{p}<0.05 ;$ and GE-MC $\mathrm{t}_{\mathrm{s}}=-7.05$, df $=94, \mathrm{p}<0.05$; Table 3), whereas the number of $\mathrm{N}$-units was significantly greater in the GE context than in the MC context $\left(\mathrm{t}_{\mathrm{s}}=3.53\right.$, df $=94, \mathrm{p}<0.05$; Table 3$)$. The frequency measures did not show a clear pattern of differentiation between the contexts. Except for the $\mathrm{N}$ - and T-units there were no significant interaction effects between context and individual (N-units: F15,168 $=2.7, \mathrm{p}=0.001$; $\mathrm{T}$ units: $\mathrm{F} 15,168=2.4, \mathrm{p}=0.003)$.

A further question is whether males showed similar patterns in call differences between the four contexts. To answer this question we performed two-way factorial ANOVAs with the first and second discriminant function as dependent variables, respectively, and call context and male identity as independent factors. It turned out that there were no significant interaction effects between individual and context on either discriminant function (function 1: $\mathrm{F} 1,135=0.69, \mathrm{p}=0.69$; function $2: \mathrm{F} 15,135=1.18, \mathrm{p}=0.30)$. The lack of significance indicates that all individuals show a similar pattern in loud call differences between the contexts (Fig. $4 a-d)$.

Females in the AL and GE context retrieved their infants on most occasions after hearing the loud call (Table 4, Wilcoxon signed rank test: $\mathrm{T}^{+}=152$, $\mathrm{p}<0.0001, \mathrm{n}=17$ for GE and AL, respectively. In the VR context the pattern was reversed with mothers more often not retrieving their infants $\left(\mathrm{T}^{-}=152\right.$, $\mathrm{p}<0.0001, \mathrm{n}=17)$.

\section{Discussion}

The study presented here corroborates results found for individuality in Thomas langur loud calls by Steenbeek \& Assink (1998), while taking contextual differences into account. In the present study, however, more acoustic variables were found to discriminate between individuals. The discriminant analyses indicated that the frequency measures (N1in and N2in) plus the number of N-and T-units were the most important variables to distinguish among individuals. Therefore, as in other primates, the loud calls appear to convey information that allows for individual recognition (e.g. P. troglodytes: Marler \& Hobbett 1975; Hylobates klossi: Tenaza 1976; P. johnii: Hohmann \& Vogl 1991; Papio cynocephalus: Fischer et al. 2001).

Individual recognition of Thomas langur loud calls could be functional for the males given that they have differentiated relationships with each neighbour 

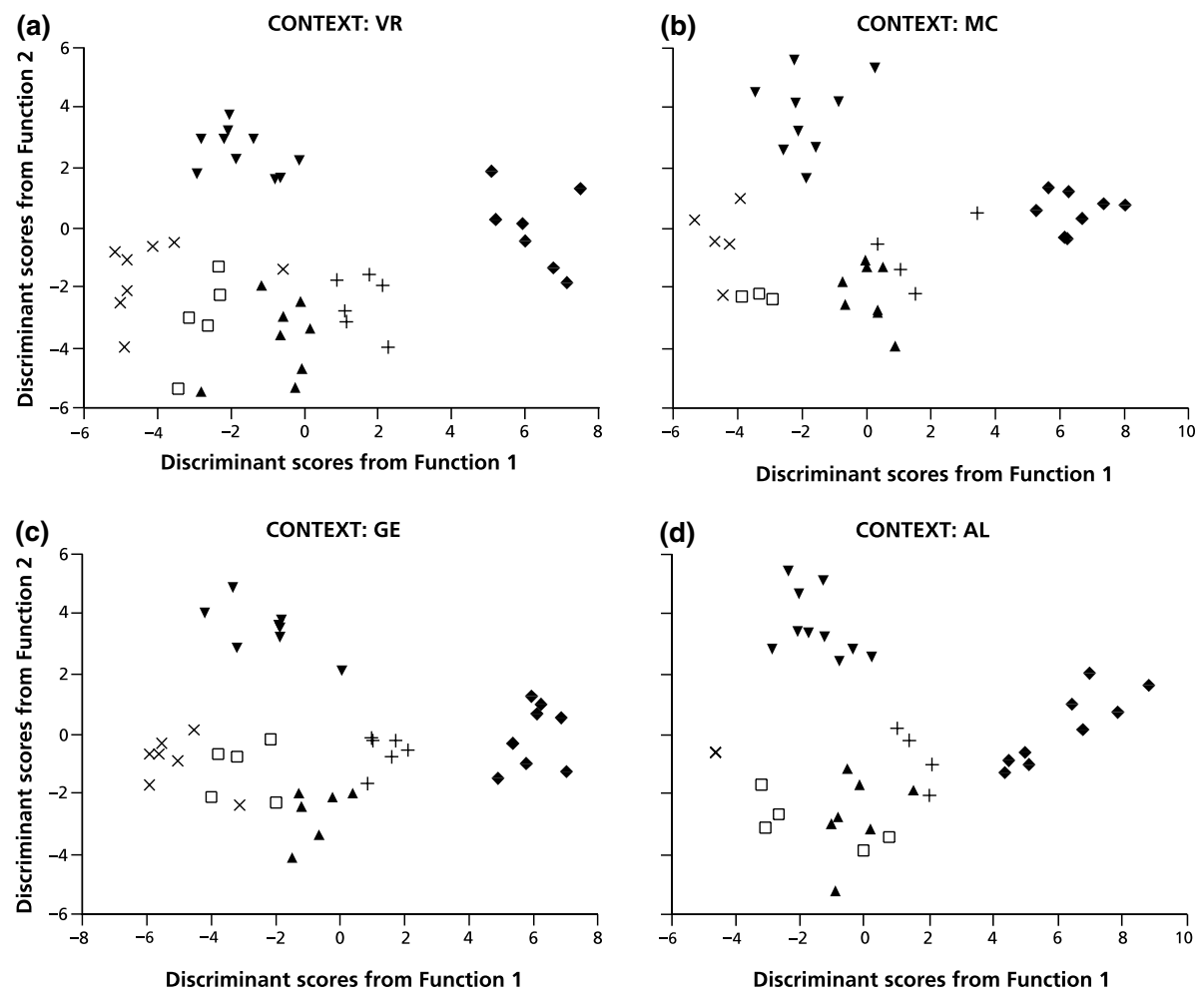

Fig. 4: (a-d) Scatter plots of individual scores for discriminant function 1 against discriminant function 2 for each context separately

(Steenbeek 1999a). Indeed, the number of aggressive encounters differs between neighbours, with more aggression being directed towards neighbours that are met less frequently (S.A. Wich, unpubl. data).

The ability to distinguish among loud calls of different individuals is also likely to be functional for females, because some males are more likely than others to make infanticidal attacks (Steenbeek 1999a). McComb et al. (1993) also suggested such benefits for lions $(P$. leo). This idea is supported by playback studies conducted on the langur groups used in this study, indicating that Thomas langurs can discriminate among individuals with different loud calls and react more cautiously towards potentially infanticidal males (Wich et al. 2002; S. A. Wich, unpubl. data).

Another major result we found is that loud calls given in different behavioural contexts were acoustically distinct (cf. Norcross et al. 1999; Fischer et al. 2001). Interestingly, the discriminant analyses indicated that temporal, but not frequency, variables distinguished best among contexts. However, loud calls given in different contexts were not completely distinct. Rather, their acoustic characteristics overlapped. This indicates a graded vocal system of loud call types, 
Table 4: The number of occasions on which females retrieved (ir) vs. did not retrieve (no ir) their infants after their own male gave a loud call in the different contexts

\begin{tabular}{|lllrllll|}
\hline Individual & Group & VR-ir & VR-no ir & AL-ir & AL-no ir & GE-ir & GE-no ir \\
\hline 1 & 1 & 4 & 8 & 5 & 1 & 13 & 3 \\
2 & 1 & 5 & 4 & 7 & 1 & 11 & 3 \\
3 & 2 & 3 & 7 & 3 & 0 & 9 & 4 \\
4 & 2 & 2 & 9 & 4 & 0 & 12 & 5 \\
5 & 3 & 1 & 7 & 2 & 0 & 17 & 3 \\
6 & 3 & 3 & 11 & 6 & 2 & 12 & 2 \\
7 & 4 & 7 & 12 & 5 & 1 & 7 & 4 \\
8 & 4 & 5 & 7 & 2 & 3 & 12 & 4 \\
9 & 5 & 3 & 8 & 2 & 0 & 15 & 3 \\
10 & 5 & 4 & 14 & 4 & 0 & 12 & 1 \\
11 & 6 & 2 & 7 & 4 & 1 & 14 & 4 \\
12 & 6 & 2 & 7 & 5 & 1 & 12 & 2 \\
13 & 7 & 3 & 8 & 3 & 0 & 1 & 2 \\
14 & 7 & 3 & 9 & 3 & 1 & 17 & 3 \\
15 & 8 & 4 & 12 & 2 & 0 & 14 & 2 \\
16 & 8 & 7 & 16 & 3 & 0 & 13 & 2 \\
17 & 9 & 5 & 17 & 5 & 2 & 13 & 1 \\
\hline
\end{tabular}

like those found in P. papio (Byrne 1982) and Macaca sylvanus (Hammerschmidt $\&$ Fischer 1998). To classify a call into a certain context, the receiver may have to know the individual, as apparently is the case in spider monkey (A. geoffroyi) whinnies, which show contextual variation superimposed on individual distinctiveness (Hammerschmidt \& Fischer 1998; Teixidor \& Byrne 1999).

Several temporal characteristics allow distinction among the four loud call types, despite the occurrence of graded variation and despite their overall similarity. These are duration, the number of $\mathrm{N}$-units, the number of $\mathrm{T}$-units and the time intervals N10-N1 and N10-N8. Differences in the number of N- and $\mathrm{T}$-units are responsible for overall duration.

A high number of T-units in MC loud calls is expected. These calls should be heard over longer distances than GE and AL calls, and the tonal sounds in the T-units have better propagation than non-tonal ones (Waser \& Brown 1986). Loud calls given in the AL and GE contexts are likely to be directed to either the group of the caller (AL; S.A. Wich unpubl. data) or both the group of the caller and the other group that is in close proximity (GE). Therefore, these calls do not need to be propagated over long distance, which makes it unnecessary to give many T-units.

In support of the hypothesis that the distance of the recipient is related to the number of T-units we found strong positive correlations between the distance of the recipient and the number of T-units in the VR context. This indicates that males are able to manipulate certain parts of their calls in direct relation to the distance of a neighbour, even within the same context. Because the distance between groups may vary considerably in the VR context, the number of T-units 
varies extensively. This strong variation in T-units causes the low predicted group membership value for the VR context in relation to the other contexts. In addition, we hypothesize that the number of $\mathrm{N}$-units is an indication of the 'urgency' of the call. In a non-dangerous situation (MC), a smaller number of $\mathrm{N}$-units is given than in a potentially dangerous situation (GE), in which females need to react swiftly with collecting their infants and grouping together. Therefore, the first part of the call could logically be more important when a swift reaction is needed.

The possible biological significance of the loud call variation between contexts is strengthened by the observation of female responses indicating that females might actually perceive contextual differences in loud calls. Female infant collection occurred significantly more often in threatening situations such as possible predation and between-group encounter (possible infanticide) than in a situation in which the neighbouring male is far away (vocal response). Although playback experiments are needed to exclude the possibility that females use other (non-vocal) cues to react.

In conclusion, the results presented here show that there are both individual and contextual differences in male loud call characteristics and that these might be perceived and reacted to appropriately by females. Because females may have independent means to assess contexts, measurement of female responses to playbacks of loud calls associated with different contexts are needed to determine whether call features really influence female responses.

\section{Acknowledgements}

We gratefully acknowledge the cooperation and support of the Indonesian Institute of Science (LIPI, Jakarta), the Indonesian Nature Conservation Service (PHPA) in Jakarta, Medan and Kutacane (Gunung Leuser National Park Office), Universitas National (UNAS, Jakarta) and the Leuser Development Programme (LDP, Medan), especially M. Griffiths and Dr K. Monk. We also thank the LDP staff in Ketambe, especially Abu Hanifah Lubis, for providing an excellent research environment and strong logistical support. We thank Usman, Samsu, Rahimin, Arwin, Saskia, Linda, Frauke for helping with data collection. Financial support to SW was generously provided by the Netherlands Foundation for the Advancement of Tropical Research (WOTRO), the Treub Foundation, the Dobberke Foundation and the Lucie Burgers Foundation for Comparative Behaviour Research. SK was financially supported by Helsinki University Faculty of Science, Nature Research Association Vanamo and Niilo Helander Foundation. We thank Jan van Hooff and Liesbeth Sterck for giving valuable suggestions during all phases of this research. Julia Fischer, Robert Seyfarth, Lotta Sundström and five anonymous reviewers gave valuable comments on earlier versions of the manuscript. We thank the European Commission and the Government of Indonesia as the funding agencies for the Leuser Development Programme.

\section{Literature Cited}

Byrne, R. W. 1982: Primate vocalisations; structural and functional approaches to understanding. Behaviour 80, 241-258.

Chapman, C. A. \& Lefebvre, L. 1990: Manipulating foraging group size: spider monkey food calls at fruiting trees. Anim. Behav. 39, 891-896.

Chapman, C. A. \& Weary, D. M. 1990: Variability in spider monkeys' vocalization may provide basis for individual recognition. Am. J. Primatol. 22, 279-284. 
Clark, A. \& Wrangham, R. 1993: Acoustic analyses of wild chimpanzee pant-hoots: do Kibale forest chimps have an acoustically distinct food-arrival pant-hoot? Am. J. Primatol. 31, 99-109.

Fischer, J., Hammerschmidt, K., Cheney, D. L. \& Seyfarth, R. M. 2001: Acoustic features of female baboon barks. Ethology 107, 33-54.

Hammerschmidt, K. \& Fischer, J. 1998: The vocal repertoire of Barbary macaques: a quantitative analysis of a graded signal system. Ethology 104, 203-216.

Hochberg, Y. 1988: A sharper Bonferroni procedure for multiple tests of significance. Biometrika 75, $800-802$.

Hohmann, G. \& Vogl, L. 1991: Loud calls of male Nilgiri langurs (Presbytis johnii): age-, individual-, and population-specific differences. Int. J. Primatol. 12, 503-524.

Marler, P. \& Hobbet, L. 1975: Individuality in a long-range vocalization of wild chimpanzee. Z. Tierpsychol. 38, 97-109.

McComb, K., Pusey, A., Packer, C. \& Grinnell, J. 1993: Female lions can identify potentially infanticidal males from thier roars. Proc. R. Soc. Lon. B. 252, 59-64.

Norcross, J. \& Newman, J. 1993: Context- and sex-specific differences in the acoustic structure of common marmoset (Callithrix jacchus). Am. J. Primatol. 30, 135-146.

Norcross, J., Newman, J. \& Cofrancesco, L. M. 1999: Context and sex differences exist in the acoustic stucture of phee calls by newly-paired common marmosets (Callithrix jacchus). Am. J. Primatol. 49, $165-181$.

Rijksen, H. 1978: A Field Study on Sumatran Orang-Utans (Pongo pygmaeus abelli, Lesson 1827): Ecology, Behaviour and Conservation. Veenman, Wageningen.

van Schaik, C. P. \& Mirmanto, E. 1985: Spatial variation in the structure and litterfall of a Sumatran rainforest. Biotropica 17, 196-205.

van Schaik, C. P., Assink, P. \& Salafsky, N. 1992: Territorial behavior in south-east Asian langurs: resource defence or mate defence? Am. J. Primatol. 26, 233-242.

Snowdon, C. T. \& Cleveland, J. 1980: Individual recognition of contact calls by pygmy marmosets. Anim. Behav. 28, 717-727.

Steenbeek, R. 1999a: Female choice and male coercion in wild Thomas's langurs. PhD Thesis, Utrecht Univ., Utrecht.

Steenbeek, R. 1999b: Tenure related changes in wild Thomas's langurs I: between-group interactions. Behaviour 136, 595-625.

Steenbeek, R. \& Assink, P. 1998: Individual differences in long-distance calls of male Thomas langurs (Presbytis thomasi). Folia Primatol. 69, 77-80.

Steenbeek, R., Assink, P. \& Wich, S. A. 1999: Tenure related changes in wild Thomas's langurs II: loud calls. Behaviour 136, 627-650.

Sterck, E. H. M. 1995: Females, foods and fights: a socioecological comparison of the sympatric Thomas langur and long tailed macaque. PhD Thesis, Utrecht Univ., Utrecht.

Sterck, E. H. M. 1997: Determinants of female dispersal in Thomas langurs. Am. J. Primatol. 42, $179-198$.

Tabachnick, B. G. \& Fidell, L. S. 2001: Using Multivariate Statistics, 4th edn. Allyn \& Bacon, Boston.

Teixidor, P. \& Byrne, R. W. 1999: The whinny of spider monkeys: individual recognition before situational meaning. Behaviour 136, 279-308.

Tenaza, R. 1976: Songs and related behaviour of Kloss' gibbon (Hylobates klossi) in Siberut Island, Indonesia. Z. Tierpsychol. 40, 37-52.

Vercauteren-Drubbel, R. \& Gautier, J. P. 1993: On the occurrence of nocturnal and diurnal loud calls, differing in structure and duration, in Red howlers (Alouatta seniculus) of French Guyana. Folia Primatol. 60, 195-209.

Waser, P. M. 1977: Individual recognition, intragroup cohesion and intergroup spacing: evidence from sound playback to forest monkeys. Behaviour 60, 28-74.

Waser, P. M. \& Brown, C. H. 1986: Habitat acoustics and primate communication. Am. J. Primatol. 10, 135-154.

Wich, S. A., Assink, P. R., Becher, F. \& Sterck, E. H. M. (2002) Playbacks of loud calls to wild Thomas langurs (Primates; Presbytis thomasi): the effect of familiarity. Behaviour 139, $79-87$. 
Ydenberg, R., Giraldeau, L. \& Falls, J. 1988: Neighbours, strangers and the asymmetric war of attrition. Anim. Behav. 36, 343-347.

Received: February 20, 2002

Initial acceptance: May 6, 2002

Final acceptance: August 17, 2002 (L. Sundström) 